\title{
THE FOOT POSTURE INDEX BETWEEN ELITE ATHLETIC AND SEDENTARY COLLEGE STUDENTS
}

\author{
Yi-Liang Kuo ${ }^{1}$ and Yves Shen-Feng Liu ${ }^{2}$ \\ ${ }^{1}$ Department of Physical Therapy, College of Medicine, \\ National Cheng Kung University, Tainan, Taiwan \\ ${ }^{2}$ You Cheng Orthopedic Clinic, Taipei, Taiwan
}

Original scientific paper

UDC: $616.7: 796$

\begin{abstract}
:
Sports participation may lead to musculoskeletal adaptation and alter foot posture; however, the effect of high impact sports on foot posture has not fully been understood yet. The purpose of this study was to investigate the difference in foot posture between elite collegiate athletes participating in high impact sports and sedentary college students using the Foot Posture Index (FPI). Foot postures of 30 elite collegiate athletes of high impact sports and 30 sedentary controls were observed in standing and evaluated using the 6-item FPI. The FPI-6 score for the athletic group was statistically significantly higher than that for the sedentary group $(\mathrm{z}=-2.282, \mathrm{p}=.022)$. Participation in high impact sports can be associated with a more pronated foot posture; however, most college students, whether athletic or sedentary, had normal feet as categorized by the FPI- 6 .
\end{abstract}

Key words: pronated foot, sports participation, Foot Posture Index

\section{Introduction}

Foot posture has been a focus of research in sports and health science. It is generally believed that misalignment of the foot and faulty biomechanics are interrelated and both factors subsequently may predispose the foot or lower extremity to musculoskeletal injury (Bolgla \& Malone, 2004). Therefore, foot posture is commonly assessed for injury prevention and intervention in clinical practice.

Most sports, especially those that involve running and jumping, places a tremendous amount of force on the foot that exceeds several times one's body weight (Cloak, Galloway, \& Wyon, 2010; Guido \& Werner, 2012; Hong, Wang, Lam, \& Cheung, 2013). These forces have been shown to result in musculoskeletal adaptation and misalignment of the lower extremity in adolescent boys who practiced competitive sports (Thijs, Bellemans, Rombaut, \& Witvrouw, 2012). However, only a few studies have investigated the relationship between sports participation and foot posture. Kulthanan, Techakampuch, and Bed (2004) and Aydog et al. (2004) reported no statistically significant difference in foot posture between athletes and nonathletes based on two measurements including the flat index and sole arch index. In a further study, the same group of researchers showed that the sole arch index of gymnasts and handball players were significantly lower than those of non-athletic controls (Aydog, Tetik, Demirel, \& Doral, 2005b). However, the sole arch index of wrestlers was significantly different from those of other athletes and higher than the non-athletic controls. Kulthanan et al. (2004) did not specify what type of sports their athletes had participated in. It is possible that their study included athletes participating in various sports with different degrees of impact loading. As a result, the effect of high impact sports on foot posture was not detected in the athletic group. Similarly, the degree of mechanical loading was different in the study of Aydog et al. (2005b).

In a study comparing the bone mineral density among athletes and non-athletic controls, Torstveit and Sundgot-Borgen (2005) divided different sports into three groups based on the degree of mechanical loading. Their classification method was based on the ground reaction force data calculated by Groothausen and Siemer (1997). Gymnastics and handball are classified as high impact sports, and wrestling as a medium impact sport. Inconsistent results, found in previous studies, may be contributed to different degrees of mechanical loading in sports. Therefore, investigating the impact of sports participation on foot posture in athletes should consider the degree of mechanical loading in sports. 
Many methods, such as visual observation, radiography, and anthropometric measurements, have been investigated to measure foot posture (Razeghi $\&$ Batt, 2002). The methods used in previous studies that investigated the relationship between sports participation and foot posture are based on measurement of width or area of contact on the imprint of the foot (Aydog, et al., 2004, 2005b; Kulthanan, et al., 2004). The validity of the footprint method has been questioned because footprint variation insufficiently explained arch height measurement (Hawes, Nachbauer, Sovak, \& Nigg, 1992).

Foot Posture Index (FPI) is a criterion-based observational scoring system (Redmond, Crosbie, \& Ouvrier, 2006). The FPI criteria require the examiner to observe static foot posture and rate foot morphology in all three cardinal planes. The FPI includes six items and each item is scored on a 5-point scale, with a score of -2 for signs of high supination and +2 for signs of high pronation (range, -2 to +2 ) (Table 1). Previous studies examining the reliability of the FPI- 6 showed that the FPI-6 demonstrated excellent intra-rater reliability (ICC =.81-.94) and moderate to good inter-rater reliability (ICC $=.53-.74)$ across children, adolescent and adult age groups (Evans, Copper, Scharfbillig, Scutter, \& Williams, 2003; Morrison \& Ferrari, 2009). Moreover, when compared to a three-dimensional electromagnetic motion analysis system, the FPI- 6 predicted $64 \%$ and $41 \%$ of the variation in static and dynamic foot position, respectively (Redmond, et al., 2006). More recently, the FPI-6 has been used to investigate foot posture in athletes (Bravo-Aguilar, Gijon-Nogueron, Luque-Suarez, \& Abian-Vicen, 2016; Cherati, Dousti, \& Younespour,
2016; Cowley \& Marsden, 2013) and patients with knee osteoarthritis (Hatfield, et al., 2016; Hsieh \& Lee, 2016).

This study aimed to compare the foot posture between elite collegiate athletes, who participated in high impact sports, and sedentary controls using the FPI-6. We hypothesized that elite collegiate athletes participating in high impact sports are more likely to have pronated feet than sedentary college students because repetitive mechanical loading over time may cause a gradual decrease in tension of the supporting ligaments and also increase joint laxity (Solomonow, 2004).

\section{Methods}

\section{Participants}

Two groups of college students, 30 in each group, were recruited to participate in this study using the method of purposive sampling. The sample size calculation was based on a previous study investigating the foot posture of 30 halfmarathon runners. The mean FPI- 6 score of the left foot significantly increased by 1.7 , from $1.8 \pm 1.5$ pre-race to $3.4 \pm 2.3$ post-race before and after a prolonged run (Cowley \& Marsden, 2013). Therefore, we estimated that to detect an effect size of $1.7 / 2.3=.74$ would require 30 participants in each group (power=.8; $\alpha=.05$ ). The athletic group was defined as college students that were members of varsity university teams and had competed in a national-level competition of high impact sports within the past three years. High impact sports included badminton, basketball, and volleyball (Torstveit \& Sundgot-Borgen, 2005). The seden-

Table 1. Criteria of the Foot Posture Index (FPI-6)

\begin{tabular}{|c|c|}
\hline FPI scoring criteria & Description \\
\hline Talar head palpation & $\begin{array}{l}-2=\text { talar head palpable on lateral side/but not on medial side } \\
0=\text { talar head equally palpable on lateral and medial side } \\
+2=\text { talar head not palpable on lateral side/but palpable on medial side }\end{array}$ \\
\hline $\begin{array}{l}\text { Supra and infra lateral malleolar } \\
\text { curvature }\end{array}$ & $\begin{array}{l}-2=\text { curve below the malleolus either straight or convex } \\
0=\text { both infra and supra malleolar curves roughly equal } \\
+2=\text { curve below the malleolus markedly more concave than curve above the malleolus }\end{array}$ \\
\hline Calcaneal frontal plane position & $\begin{array}{l}-2=\text { more than an estimated } 5^{\circ} \text { inverted } \\
0=\text { vertical } \\
+2=\text { more than an estimated } 5^{\circ} \text { everted }\end{array}$ \\
\hline $\begin{array}{l}\text { Bulging in the region of the } \\
\text { talonavicular joint (TNJ) }\end{array}$ & $\begin{array}{l}-2=\text { area of TNJ markedly concave } \\
0=\text { area of TNJ flat } \\
+2=\text { area of TNJ bulging markedly }\end{array}$ \\
\hline $\begin{array}{l}\text { Height and congruence of the medial } \\
\text { longitudinal arch }\end{array}$ & $\begin{array}{l}-2=\text { arch high and acutely angled towards the posterior end of the medial arch } \\
0=\text { arch height normal and concentrically curved } \\
+2=\text { arch very low with flattening in the central portion }- \text { arch making ground contact }\end{array}$ \\
\hline $\begin{array}{l}\text { Abduction/adduction of the forefoot } \\
\text { on the rearfoot }\end{array}$ & $\begin{array}{l}-2=\text { no lateral toes visible } \\
0=\text { medial and lateral toes equally visible } \\
+2=\text { no medial toes visible }\end{array}$ \\
\hline
\end{tabular}


tary group was defined as college students that did not participate in any sports-related activities and were not involved in any regular exercise. Participants with a history of orthotic use for the lower extremity, pain during measurement, or neuromusculoskeletal injury of the lower extremity within the last six months were excluded. The Research Ethics Committee at the local hospital approved this study. Prior to the involvement in this study, participants were informed of the purpose of this research and signed a written consent form.

\section{Procedure}

Data collection was conducted in the university's laboratory. First, participants were asked to provide their basic information about age, gender, body height, body mass, and sport participation. Participants were then instructed to remove their shoes and socks for foot posture measurement. The FPI-6 scores were recorded by examining the rearfoot and forefoot of the dominant leg (Redmond, 2005). Rearfoot examination was done by palpating the talar head, observing the curves above and below the lateral malleolus, and determining the position of inversion/eversion of the calcaneus bone. Forefoot examination noted the prominence of the talonavicular joint, congruences of the medial longitudinal arch, and abduction/adduction of forefoot on rearfoot. The total score was then calculated and classified based on the reference values suggested by Redmond (2005) as "highly pronated" with a score of $\geq+10$, "pronated" with scores of +6 to +9 , "normal" with scores of 0 to +5 , "supinated" with scores of -1 to -4 , or "highly supinated" with scores of $\leq-5$. To minimize measurement errors, foot posture measurements were performed by a trained physical therapist student (YL). Prior to data collection, an intra-rater reliability study was undertaken on 10 healthy participants. The intraclass correlation coefficient $\left(\mathrm{ICC}_{3,1}\right)$ was $.912(95 \%$ $\mathrm{CI}=.792-.964)$ indicating excellent intra-rater reliability.

\section{Statistical analysis}

Statistical analysis was performed using the SPSS (version 17, IBM). Categorical data was expressed as frequencies and percentages of the total number of participants. Continuous data was summarized using either mean and standard deviations (normally distributed data) or median and interquartile range (skewed data). Pearson chi-square was used to examine the proportion of gender between the groups, and independent $t$-test (or equivalent non-parametric test) was used to examine the other demographic data. The total scores of the FPI-6 were not normally distributed, as determined by the Kolmogorov-Smirnov test ( $p>05)$. Therefore, the Mann-Whitney U test was used to examine the difference in the total score of the FPI- 6 between the groups. Significance level was set at a p-value of 05 .

\section{Results}

The mean age, body height, body mass and body mass index (BMI) of all participants were $21.2 \pm 1.7$ years, $166.7 \pm 7.0 \mathrm{~cm}, 59.8 \pm 8.4 \mathrm{~kg}$, and $21.5 \pm 2.7 \mathrm{~kg} / \mathrm{m}^{2}$, respectively. Table 2 summarizes demographic data of both groups. On average, the athletic group was 1.5 years older than the sedentary group $(\mathrm{p}=.001)$. Both groups were similar in height, weight, and BMI ( $\mathrm{p}>.05)$. Of 30 participants in the athletic group, $18(60 \%)$ were volleyball players, six (20\%) were basketball players, four $(13.3 \%)$ were badminton players, and two $(6.7 \%)$ were tennis players.

The result of the Mann-Whitney U test showed that the athletic group had a higher FPI- 6 score than the sedentary group $(\mathrm{z}=-2.282, \mathrm{p}=.022)$. The median (interquartile range) of the FPI- 6 for the athletic and sedentary groups was 3.5 (3) and 2 (3), respectively. Figure 1 shows the distribution of the FPI-6 total score in both groups. Twenty-four ( $80 \%)$ participants in the athletic group had a FPI-6 total score within the normal range $(0$ to +5$)$. The other

Table 2. Demographic data of participants in the athletic and sedentary groups

\begin{tabular}{lcccc}
\hline Characteristics & Athletic group & Sedentary group & Statistics & $p$-value \\
\hline Gender & & & & \\
$\quad$ Male & $11,36.7 \%$ & $16,53.3 \%$ & $\chi^{2}=1.684$ & .194 \\
$\quad$ Female & $19,63.3 \%$ & $14,46.7 \%$ & & \\
Age (year) & $22(3)$ & $21(1)$ & $z=-3.202$ & .001 \\
Body height $(\mathrm{cm})$ & $167.9 \pm 7.3$ & $165.6 \pm 6.5$ & $t=-1.315$ & .350 \\
Body mass $(\mathrm{kg})$ & $60.8 \pm 7.6$ & $58.8 \pm 9.1$ & $t=-.943$ & .194 \\
Body mass index $\left(\mathrm{kg} / \mathrm{m}^{2}\right)$ & $21.5 \pm 1.9$ & $21.5 \pm 3.4$ & $t=-.058$ & .954 \\
\hline
\end{tabular}




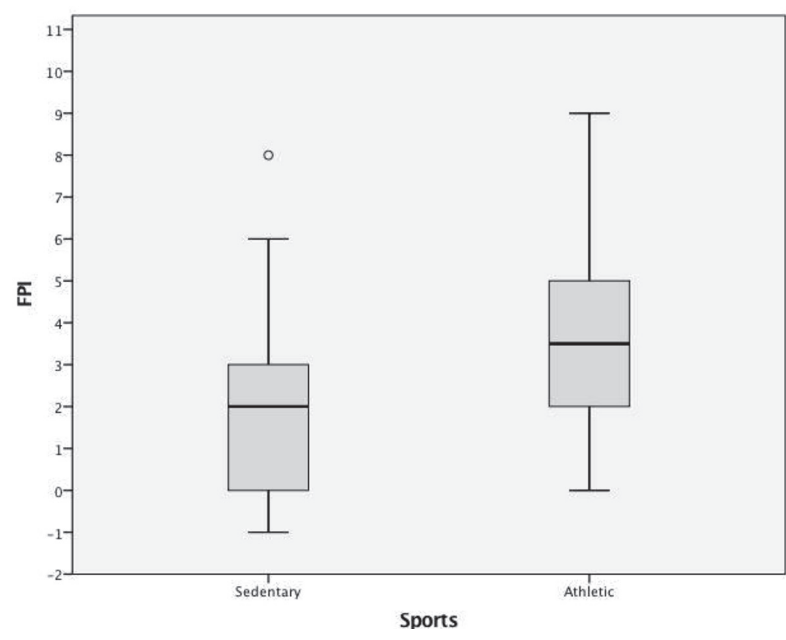

Figure 1. Boxplots of FPI-6 scores for the athletic and sedentary groups.

six $(20 \%)$ participants in the athletic group had a FPI score within the 'pronated' foot range ( +6 to +9 ). The numbers (percentage) of participants having a 'pronated', 'normal', and 'supinated' foot posture in the sedentary group were $2(6.7 \%), 26$ $(86.7 \%)$, and $2(6.7 \%)$, respectively.

\section{Discussion and conclusions}

This study was performed to determine whether foot posture of college students involved in high impact sports in general was different from foot posture of sedentary controls. The result of a statistically significantly higher FPI-6 score in the athletic group supports our hypothesis that high impact sports participation can be associated with a pronated foot posture in college students. The statistically significant age difference between the athletic and sedentary groups raises a concern, whether age might be a confounding factor to the result. Indeed, foot posture varies with age (Redmond, Crane, \& Menz, 2008; Staheli, Chew, \& Corbett, 1987). A previous study discovered the U-shaped relationship between age and logit score of the FPI- 6 since individuals aged over 60 years or less than 18 years had a tendency toward a more pronated foot posture (Redmond, et al., 2008). Our participants were within the age range where there was no age-related variation in foot posture, therefore the possible confounding effect of age on foot posture was negligible.

The median $(+3.5)$ of the FPI- 6 for the dominant leg of elite collegiate athletes in this study was similar to the previously reported median (+3) in adult athletes (Cowley \& Marsden, 2013). However, it is worth noting that the majority of our participants had a FPI score within the normal range and none had a FPI- 6 score greater than +10 or less than -3 . These values correspond to two standard deviations from the mean, which were considered the cut-off points for pathological foot posture (Redmond, et al., 2008). Our exclusion criteria regarding the participants with musculoskeletal symptoms might have contributed to this finding and the small between-group difference in the FPI-6 score.

The result of this study disagrees with those of previous studies (Aydog, et al., 2004; Kulthanan, et al., 2004), showing no significant difference in foot posture between athletes and non-athletic controls. As discussed previously, Kulthanan et al. (2004) might have included athletes participating in various sports with different degrees of impact loading. As a result, the effect of high impact sports on foot posture was not detected in the athletic group. The discrepancy between the study of Aydog et al. (2004) and ours could not be explained by different degrees of mechanical loading in sports. Both studies examined athletes involved in high impact sports except that Aydog et al. (2004) focused on adolescent basketball players and we investigated collegiate athletes. Because musculoskeletal adaptation requires time (Solomonow, 2004), elite collegiate athletes in our study may have sustained more years of intense training. As a result, they might be presented with a more noticeable change in foot posture than adolescent players when compared to the non-athletic group.

The extent to which sport-induced mechanical loading would affect foot posture of athletes is complex because the response of the ligament to mechanical loading is dependent on an uncertain dose-duration-rest formula (Solomonow, 2004). When the ligament is subjected to repetitive mechanical loading over time, the resulting hysteresis can cause a gradual decrease of tension in the ligaments and develop joint laxity. This phenomenon was observed in half-marathon runners (Cowley \& Marsden, 2013). Their FPI-6 scores significantly increased following the race, suggesting a more pronated foot posture under weight-bearing conditions. However, with sufficient rest and recovery, repetitive mechanical loading can stimulate metabolism and increase strength of the ligaments. Similarly, certain muscles in the foot and ankle that have a lowering or elevating effect on the medial longitudinal arch can be strengthened or inhibited through sports participation and training (Aydog, et al., 2005a; Van Boerum \& Sangeorzan, 2003). Further studies with other measurements such as muscle strength or joint range of motion are needed to explore possible mechanisms explaining the observed changes in foot posture.

Although the purpose of this study was not to examine the reliability of the FPI-6, the student investigator who received two-hour training from an experienced physical therapist achieved excellent intra-rater reliability with the FPI-6 tool. This finding demonstrated the FPI- 6 being simple to 
use and reliable. Some studies have used the FPI to identify risk factors for sports-related injuries (Cain, Nicholson, Adams, \& Burns, 2007; Yates \& White, 2004). Yates and White (2004) found a positive correlation between pronated feet and medial tibial stress syndrome in naval recruits. Cain et al. (2007) found that the FPI-6 score of less than two (supinated foot) were significantly associated with increased risk of overuse injury in adolescent male indoor football players. Although these studies showed opposite findings regarding the specific foot posture associated with lower extremity injury, these studies support the use of the FPI in clinical settings. Hence, the result of the current study would be useful for clinicians preventing or managing lower extremity injury in elite athletes who participate in high impact sports.

There are some limitations of this study. First, there is clearly a lack of agreement on the ideal method for foot posture measurement. The FPI-6 has advantages of being simple to use, reliable, and valid, but also has its limitations. The FPI-6 is conducted in the weight-bearing position, and does not help to differentiate between rigid and flexible flat feet (Evans, et al., 2003). Second, we did not include another athletic group involved in low impact sports. Because of the cross-sectional study design, we also could not infer the causality between sports-induced mechanical loading and altered foot posture. The natural selection process might exclude athletes with less than optimal foot posture for a specific sport or those athletes simply failed to achieve the elite level of competition. Future longitudinal studies would be required to draw any definitive conclusion.

Elite collegiate athletes involved in high impact sports had a significantly higher FPI-6 score than sedentary controls, suggesting that participation in high impact sports can be associated with a more pronated foot posture. However, most college students, whether athletic or sedentary, had normal feet as categorized by the FPI- 6 .

\section{References}

Aydog, S.T., Demirel, H.A., Tetik, O., Aydog, E., Hascelik, Z., \& Doral, M.N. (2004). The sole arch indices of adolescent basketball players. Saudi Medical Journal, 25, 1100-1102.

Aydog, S.T., Ozcakar, L., Tetik, O., Demirel, H.A., Hascelik, Z., \& Doral, M.N. (2005a). Relation between foot arch index and ankle strength in elite gymnasts: A preliminary study. British Journal of Sports Medicine, 39, e13.

Aydog, S.T., Tetik, O., Demirel, H.A., \& Doral, M.N. (2005b). Differences in sole arch indices in various sports. British Journal of Sports Medicine, 39, e5.

Bolgla, L.A., \& Malone, T.R. (2004). Plantar fasciitis and the windlass mechanism: A biomechanical link to clinical practice. Journal of Athletic Training, 39, 77-82.

Bravo-Aguilar, M., Gijon-Nogueron, G., Luque-Suarez, A., \& Abian-Vicen, J. (2016). The influence of running on foot posture and in-shoe plantar pressures. Journal of the American Podiatric Medical Association, 106, 109-115.

Cain, L.E., Nicholson, L.L., Adams, R.D., \& Burns, J. (2007). Foot morphology and foot/ankle injury in indoor football. Journal of Science and Medicine in Sport, 10, 311-319.

Cherati, A.S., Dousti, M., \& Younespour, S. (2016). Association between Foot Posture Index and ankle sprain in indoor football players. Global Journal of Health Science, 8, 51426.

Cloak, R., Galloway, S., \& Wyon, M. (2010). The effect of ankle bracing on peak mediolateral ground reaction force during cutting maneuvers in collegiate male basketball players. Journal of Strength and Conditioning Research, $24,2429-2433$.

Cowley, E., \& Marsden, J. (2013). The effects of prolonged running on foot posture: A repeated measures study of half marathon runners using the Foot Posture Index and navicular height. Journal of Foot and Ankle Research, 6, 20.

Evans, A.M., Copper, A.W., Scharfbillig, R.W., Scutter, S.D., \& Williams, M.T. (2003). Reliability of the Foot Posture Index and traditional measures of foot position. Journal of the American Podiatric Medical Association, 93, 203-213.

Groothausen, J., \& Siemer, H. (1997). Influence of peak strain on lumbar bone mineral density: An analysis of 15-year physical activity in young males and females. Pediatric Exercise Science, 9, 159-173.

Guido, J.A.Jr., \& Werner, S.L. (2012). Lower-extremity ground reaction forces in collegiate baseball pitchers. Journal of Strength and Conditioning Research, 26, 1782-1785.

Hatfield, G.L., Cochrane, C.K., Takacs, J., Krowchuk, N.M., Chang, R., Hinman, R.S., \& Hunt, M.A. (2016). Knee and ankle biomechanics with lateral wedges with and without a custom arch support in those with medial knee osteoarthritis and flat feet. Journal of Orthopedic Research, 34, 1597-1605.

Hawes, M.R., Nachbauer, W., Sovak, D., \& Nigg, B.M. (1992). Footprint parameters as a measure of arch height. Foot and Ankle, 13, 22-26.

Hong, Y., Wang, S.J., Lam, W.K., \& Cheung, J.T. (2013). Kinetics of badminton lunges in four directions. Journal of Applied Biomechanics, 30, 113-118. 
Hsieh, R.L., \& Lee, W.C. (2016). Clinical effects of lateral wedge arch support insoles in knee osteoarthritis: A prospective double-blind randomized study. Medicine, 95, e3952.

Kulthanan, T., Techakampuch, S., \& Bed, N.D. (2004). A study of footprints in athletes and non-athletic people. Journal of the Medical Association of Thailand, 87, 788-793.

Morrison, S., \& Ferrari, J. (2009). Inter-rater reliability of the Foot Posture Index (FPI-6) in the assessment of the paediatric foot. Journal of Foot and Ankle Research, 2, 1-5.

Razeghi, M., \& Batt, M.E. (2002). Foot type classification: A critical review of current methods. Gait and Posture, $15,282-291$.

Redmond, A. (2005). The Foot Posture Index: User guide and manual. Retrieved September 29, 2014, from: http:// www.leeds.ac.uk/medicine/FASTER/z/pdf/FPI-manual-formatted-August-2005v2.pdf

Redmond, A.C., Crane, Y.Z., \& Menz, H.B. (2008). Normative values for the Foot Posture Index. Journal of Foot and Ankle Research, 1, 6 .

Redmond, A.C., Crosbie, J., \& Ouvrier, R.A. (2006). Development and validation of a novel rating system for scoring standing foot posture: The Foot Posture Index. Clinical Biomechanics, 21, 89-98.

Solomonow, M. (2004). Ligaments: A source of work-related musculoskeletal disorders. Journal of Electromyography and Kinesiology, 14, 49-60.

Staheli, L.T., Chew, D.E., \& Corbett, M. (1987). The longitudinal arch. A survey of eight hundred and eighty-two feet in normal children and adults. Journal of Bone and Joint Surgery American, 69, 426-428.

Thijs, Y., Bellemans, J., Rombaut, L., \& Witvrouw, E. (2012). Is high-impact sports participation associated with bowlegs in adolescent boys? Medicine and Science in Sports and Exercise, 44, 993-938.

Torstveit, M.K., \& Sundgot-Borgen, J. (2005). Low bone mineral density is two to three times more prevalent in non-athletic premenopausal women than in elite athletes: A comprehensive controlled study. British Journal of Sports Medicine, 39(5), 282-287.

Van Boerum, D.H., \& Sangeorzan, B.J. (2003). Biomechanics and pathophysiology of flat foot. Foot and Ankle Clinics, 8, 419-430.

Yates, B., \& White, S. (2004). The incidence and risk factors in the development of medial tibial stress syndrome among naval recruits. American Journal of Sports Medicine, 32, 772-780.

Submitted: June 11, 2015

Accepted: March 1, 2017

Published Online First: September 21, 2017

Correspondence to:

Yi-Liang Kuo, P.T., Ph.D.

Department of Physical Therapy, College of Medicine, National Cheng Kung University

No. 1, University Road, Tainan City 701, Taiwan

Phone: +886 6-2353535 ext. 6251

Fax: +886 6-2370411

E-mail: kuo.yiliang@gmail.com 